\title{
Parenting methods in relation to norm awareness, social success, and perspectives of family in adulthood
}

\author{
Kazuo Nishimura ${ }^{1} \cdot$ Tadashi Yagi $^{2} \cdot$ Makoto Yano $^{3}$
}

Received: 31 March 2020 / Accepted: 31 July 2020

(C) The Author(s) 2020

\begin{abstract}
The importance of parenting methods applied in the home to child development is broadly acknowledged. However, there has not been much empirical research showing how parenting methods later relate to personality formation and social success in adulthood. In this study, we asked adults in Japan to recall messages received from parents during early childhood, and we then tested the strength of the relationships of the messages with performance in adulthood. Messages passed from parents to children were investigated from the following three aspects: (1) the norm message passed from parent to child, (2) how the message was delivered to the child, and (3) how the child received the message. Our general conclusion is that the ways in which messages are passed from parents to children in the course of a child's development can have a long-term and material effect on the child. This conclusion is valid for the message itself, for the method of delivery, and for the way in which it is received.
\end{abstract}

Keywords Parenting type $\cdot$ Norms · Income $\cdot$ Well-being · Educational attainment Ideal man $\cdot$ Ideal woman

\section{Introduction}

Most people agree that the education of children is crucial to their development. In the broadest sense, school and home form the core of education. Although opinions may differ on the methods applied, all parties acknowledge that the methods used for school education influence children's futures. This awareness is likely the reason for the existence of diverse views and various arguments on the most desirable forms of
Kazuo Nishimura
nishimura@ rieb.kobe-u.ac.jp
1 RIEB, Kobe University, Kobe, Japan
2 Faculty of Economics, Doshisha University, Kyoto, Japan
3 Research Institute of Economy, Trade and Industry, Tokyo, Japan 
school education. The importance of the home and particularly parenting is widely recognized, and recent research has begun to empirically clarify the importance of the style of parenting on a child's performance. See Chua [5] and Kim et al. [12]. The latter reports that the parenting style affects a child's academic performance and psychological stability.

No studies, however, have focused on demonstrating how types of parenting relate to personality formation and social success in adulthood as far as we are aware of. ${ }^{1}$ This study clarifies relationships between parenting methods and children's performance as adults. It introduces a fresh approach that measures the effects of various kinds of input received by children from parents during childhood that was consciously retained into adulthood. Underlying this approach is the idea that messages given by parents to a child in the course of the child's development have long-term effects on the child. Moreover, a message repeatedly given by the parents should be retained in the child's memory. That such a message should then affect lifestyle in adulthood is not surprising. The way in which a message is delivered from parents to a child may also have a long-term effect; if parents maintain consistent behavioral patterns toward a child, then the child can be expected to learn something from those patterns. Furthermore, the way in which the child receives a message from a parent probably will also affect the child's way of life as an adult. In this study, adult subjects are asked to recall their childhoods, from which we extract clear memories. From these, we verify the relationships between the messages delivered by parents to children and the children's later performance as adults.

In this study, input passed from parents to children were investigated according to three categories of characteristics: (1) norm messages to the child, (2) how the messages are delivered to the child, and (3) how the child receives the messages.

It is expected that few adults have a detailed recollection of what passed in childhood. Even people who are considered to have good recall are still likely to have biased memories, as these are thought to be filtered by their preferences. Therefore, in drawing out memories, we focused only on very basic messages.

There is little doubt about the importance of the words used in messages passed from parents to children. Therefore, we first focused on the normative words/messages relayed from parents to children (Category1). Although parenting methods differ depending on the household, the words used in each household by parents toward children in the course of day-to-day interaction tend to form patterns (Category 2). Similar tones and words are used repeatedly, and one can expect that words used repeatedly and in a similar manner are eventually retained in the child's subconscious; however, few studies have focused on this point or on the effects of the ways in which a child receives a message from the parents (Category 3 ).

Arguments have long revolved around the importance of parenting methods, a core issue in this study. Based on personal parenting experience, Chua [5] advocated "Strict" parenting, referring to Chinese mothers who undertook this type of

\footnotetext{
1 Although not concerned with parenting, Heckman [8], Heckman and Rubinstein [9], and Heckman et al. [10] showed empirical assessments of the effect of pre-school education on children's future levels of success.
} 
parenting as "Tiger Mothers". This became a significant topic of discussion in the popular press. The American developmental psychologist Baumrind [3, 4] is well known for a more academic categorization of parenting types. Baumrind classified and analyzed three types of parenting: Authoritative, Authoritarian (similar to the Tiger Mother), and Permissive. Of these, the Authoritative parent was presented as the most effective. Later, Maccoby and Martin [13] added a fourth type, Uninvolved.

Some studies have examined relationships between parenting methods and their effects, with a focus on the performance of children in childhood. In a study of Chinese-American households, Kim et al. [12] divided parenting methods into supportive, strict (or Tiger), Easygoing, and Harsh types as they examined the influence of parenting on the performance of children. Their results clearly showed that the most effective method in terms of academic achievement and psychological stability was the Supportive type, not the strict type. Ge et al. [7] studied which parenting methods are more likely to arouse depressive symptoms in children, and indicated that these methods are also important factors underlying erosion of parent-child trust. Additionally, Barber [2] examined characteristics of parenting liable to cause symptoms of depression in children, showing that psychological and behavioral limitations on children can be significant factors behind depressive symptoms and delinquency. Fuligni et al. [6] analyzed the influence of parent-child relationships on learning effects, and Meares et al. [14] and Sriram and Navalkar [17] showed how ideal images of fathers and mothers are formed. All of these studies, however, analyze the effects of parenting methods on children, but not on adulthood.

This study is based on two surveys we conducted in 2012 and 2016 in Japan. The purpose of this paper is to present an overall view of the survey results and extend the analysis presented in Nishimura et al. [15] and Nishimura and Yagi [16]. Section 2 contains a brief overview of the survey respondents and methods, and Sects. 3 and 4 present some previously reported results but with new details and analyses. Section 5 clarifies adulthood abilities in relation to the five parenting types introduced in Sect. 4, and Sect. 5 examines Strict parenting in comparison with other selected parenting types. In Sect. 6, we show how the manner in which children receive parenting affects social behavior in adulthood, and we make concluding remarks in Sect. 7.

\section{Surveys}

In February 2012 and January 2016, we surveyed adults in Japan on the teaching they received from their parents during childhood. As is explained in Introduction, input passed from parents to children were investigated according to three categories of characteristics: (1) norm messages to the child, (2) how the messages are delivered to the child, and (3) how the child receives the messages. The main focus of the 2012 survey was Category 1. The 2016 survey mainly focused on Categories 2 and 3 and their relationships to Category 1 .

The methods used for the 2012 survey are described in Nishimura et al. [15]. The 2012 survey was concerned with normative awareness instilled by parents during childhood, and the educational attainment and income of the children after they 
became employed. Questionnaires were sent through the NTTCom Online Marketing Solutions Corporation to 90,000 randomly selected users registered with NTTCom. The number of survey responses recovered was 16,427 (a response rate of $18.25 \%$ ), of which 15,949 were valid. The gender breakdown was $52.7 \%$ male and $47.3 \%$ female. Among the male respondents, $66.1 \%$ were married, and $66.5 \%$ of the female respondents were married. $56.7 \%$ of the respondents had children. The proportion of respondents with the educational attainment of an undergraduate degree or higher was $49.9 \%$, and the average age was 43.27 years (standard deviation of 11.78 years). Average pre-tax income for all respondents was JPY3,462,500 (USD30,495.59) (standard deviation JPY3,292,600 (USD28,999.21)).

The 2016 survey was part of the project "Basic Research for the Sustainable growth of the Japanese Economy," sponsored by the Research Institute of Economy, Trade and Industry. The methods used for the 2016 survey are described in detail in Nishimura and Yagi [16]. Similar to the 2012 survey, this was a web survey on parenting experienced during childhood. A core objective of the survey was to define the characteristics of the five parenting types (supportive, strict, permissive, uninvolved, and harsh). We then endeavored to ascertain how these types of parenting related to income, well-being, educational attainment, and other factors. The firm Rakuten Research sent questionnaires to 330,000 randomly selected registered site users. The number of responses received was 10,000, all of which were valid. There were 5000 responses each from male and female respondents. Among the male respondents, $54.9 \%$ were married, and $62.3 \%$ of the female respondents were married. About half of the respondents had children, and $54.6 \%$ of the males and $33.5 \%$ of the females had an undergraduate degree or higher. The average age was 45.75 years (standard deviation 13.20 years). Average pre-tax income for all respondents was JPY 2,993,700 (USD26,366.68) [standard deviation JPY 2,998,760 (USD26,411.25)].

In the 2012 survey, respondents were asked about eight typical norms, considered to be frequently talked about by Japanese parents with their children during childhood. The respondents were asked whether their parents taught them each norm during childhood. The question mode was: "Of things often said to you by adults in your life while you were a child, please indicate those which you remember still now (multiple answers accepted)". The subjects were presented with eight choices of norms and could mark all that applied. The norms were: "Greet people", "Be kind to others", "Do not lie", "Express gratitude", "Listen to your parents", "Speak in a loud voice", "Follow the rules", and "Study". If a respondent recalled having been told about a norm by a parent, the parent was deemed to have taught the norm to the respondent, and the respondent was considered to have acquired the norm to some extent. In contrast, if the subject could not recall the norm, we assumed that the parents had not taught the norm or that the teaching was insufficient, and in either case, the subject did not acquire it. For ease of expression in this paper, we labeled the former group "Exposed" and the latter group "Unexposed".

Respondents who graduated from a university or post-graduate school are defined as high-education respondents. Table 1 shows the ratio of high-education respondents to the entire group for exposure and non-exposure to each norm. The ratios of high education were significantly higher $(p<0.01)$ for the groups 
Table 1 Ratios of high-education respondents according to exposure/non-exposure to norms

\begin{tabular}{|c|c|c|c|c|c|}
\hline & Exposure to norms & No. of people & $\begin{array}{l}\text { Ratio of high } \\
\text { education }\end{array}$ & Standard error & $p$ value \\
\hline \multirow[t]{2}{*}{ Greet people } & Unexposed & 6958 & 0.51 & .00599 & \multirow[t]{2}{*}{0.001} \\
\hline & Exposed & 8991 & 0.49 & .00527 & \\
\hline \multirow[t]{2}{*}{ Do not tell lies } & Unexposed & 9378 & 0.49 & .00516 & \multirow[t]{2}{*}{0.064} \\
\hline & Exposed & 6571 & 0.51 & .00617 & \\
\hline \multirow[t]{2}{*}{ Be kind to others } & Unexposed & 12,619 & 0.49 & .00445 & \multirow[t]{2}{*}{0.035} \\
\hline & Exposed & 3330 & 0.52 & .00866 & \\
\hline \multirow[t]{2}{*}{ Express gratitude } & Unexposed & 9849 & 0.50 & .00504 & \multirow[t]{2}{*}{0.831} \\
\hline & Exposed & 6100 & 0.50 & .00640 & \\
\hline \multirow[t]{2}{*}{ Listen to your parents } & Unexposed & 10,742 & 0.50 & .00482 & \multirow[t]{2}{*}{0.040} \\
\hline & Exposed & 5207 & 0.49 & .00693 & \\
\hline \multirow[t]{2}{*}{ Speak in a loud voice } & Unexposed & 15,242 & 0.50 & .00405 & \multirow[t]{2}{*}{0.362} \\
\hline & Exposed & 707 & 0.48 & .01881 & \\
\hline \multirow[t]{2}{*}{ Follow the rules } & Unexposed & 10,040 & 0.49 & .00499 & \multirow[t]{2}{*}{0.000} \\
\hline & Exposed & 5909 & 0.52 & .00650 & \\
\hline \multirow[t]{2}{*}{ Study } & Unexposed & 11,435 & 0.48 & .00467 & \multirow[t]{2}{*}{0.000} \\
\hline & Exposed & 4514 & 0.55 & .00741 & \\
\hline
\end{tabular}

exposed to the norms "Follow the rules" and "Study" as compared to the unexposed groups, as were the norms "Be kind to others" and "Listen to your parents" $(p<0.05)$.

Income level is regarded as showing a type of evaluation by the labor market. Table 2 presents a comparison of the average pre-tax incomes of employed respondents for exposure and non-exposure to each norm. The average income of respondents who were exposed to the norms "Do not tell lies", "Be kind to others", and "Follow the rules" was significantly higher $(p<0.01)$ than it was for unexposed respondents. "Study" $(p<0.05)$ was also significantly higher.

Figure 1 is a scatter diagram showing the ratio of the average income of the group exposed to a specific norm to the average income of the unexposed group versus the ratio of the high-education ratio of the group exposed to a specific norm to the high-education ratio of the unexposed group. In terms of education and income, the greatest benefits are produced by the four norms "Do not tell lies", "Be kind to others", "Follow the rules", and "Study". Nishimura et al. [15] confirmed this conclusion through a two-stage instrumental variable method, using education as an endogenous variable and applying multiple regression analysis of determinants to income.

Figure 2 shows an income comparison of the respondent group exposed to all four of the norms "Do not tell lies", "Be kind to others", "Follow the rules", and "Study" and the group exposed to fewer than the four of the norms. The group exposed to all four norms had an average income of about JPY642,000 more per year than the other group $(p<0.01)$. 
Table 2 Average incomes according to exposure/non-exposure to norms

\begin{tabular}{|c|c|c|c|c|}
\hline & No. of people & $\begin{array}{l}\text { Average Income } \\
\text { (JPY 10,000) }\end{array}$ & Standard error & $p$ value \\
\hline \multicolumn{5}{|l|}{ Greet people } \\
\hline Unexposed & 5803 & 426.52 & 4.19 & \multirow[t]{2}{*}{0.024} \\
\hline Exposed & 7361 & 413.98 & 3.68 & \\
\hline \multicolumn{5}{|c|}{ Do not tell lies } \\
\hline Unexposed & 7686 & 398.83 & 3.48 & \multirow[t]{2}{*}{0.000} \\
\hline Exposed & 5478 & 448.52 & 4.47 & \\
\hline \multicolumn{5}{|c|}{ Be kind to others } \\
\hline Unexposed & 10,405 & 413.37 & 3.05 & \multirow[t]{2}{*}{0.000} \\
\hline Exposed & 2759 & 442.66 & 6.42 & \\
\hline \multicolumn{5}{|c|}{ Express gratitude } \\
\hline Unexposed & 8145 & 418.48 & 3.47 & \multirow[t]{2}{*}{0.635} \\
\hline Exposed & 5019 & 421.18 & 4.56 & \\
\hline \multicolumn{5}{|c|}{ Listen to your parents } \\
\hline Unexposed & 8870 & 417.52 & 3.35 & \multirow[t]{2}{*}{0.301} \\
\hline Exposed & 4294 & 423.61 & 4.89 & \\
\hline \multicolumn{5}{|c|}{ Speak in a loud voice } \\
\hline Unexposed & 12,577 & 418.57 & 2.82 & \multirow[t]{2}{*}{0.115} \\
\hline Exposed & 587 & 439.69 & 13.84 & \\
\hline \multicolumn{5}{|c|}{ Follow the rules } \\
\hline Unexposed & 8268 & 411.42 & 3.39 & \multirow[t]{2}{*}{0.000} \\
\hline Exposed & 4896 & 433.17 & 4.73 & \\
\hline \multicolumn{5}{|l|}{ Study } \\
\hline Unexposed & 9392 & 415.12 & 3.24 & \multirow[t]{2}{*}{0.012} \\
\hline Exposed & 3772 & 430.43 & 5.30 & \\
\hline
\end{tabular}

\section{Manner of message delivery to children}

To identify the characteristics of the five parenting types noted previously, we prepared 20 survey questions for the 2016 survey using questions relating to the attachment between parents and children from Armsden and Greenberg [1]. We added seven original questions, four indicated time shared by parents and children, and three defined how the parents scolded, reproved, or admonished their children. The principal factor method was applied to the responses to extract factors. Responses to each question were placed on a 5-point Likert scale, with 1 indicating "Strongly Disagree" and 5 meaning "Strongly Agree". Using the principal factor method, we extracted four factors with eigenvalues of at least 1 . We then interpreted their meanings by examining questions that showed a strong correlation with the four extracted factors.

As explained in Nishimura and Yagi [16], we interpreted the factors extracted from responses to the 20 questions on parent-child attachment as follows: 


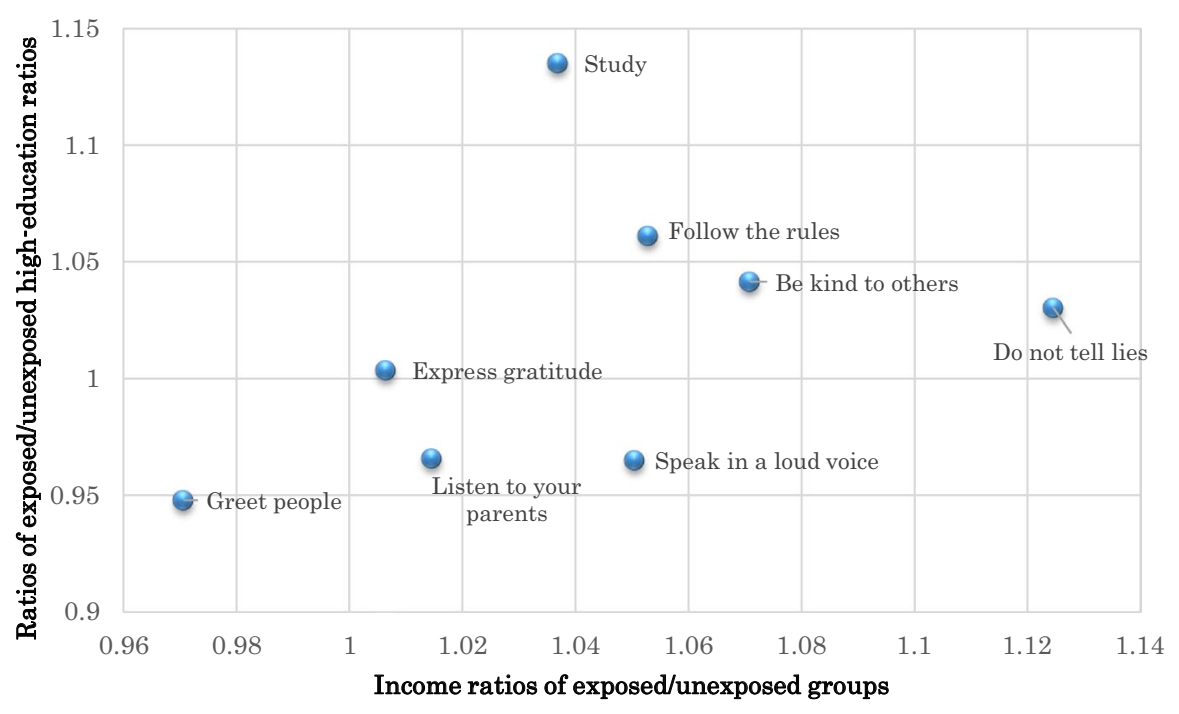

Fig. 1 Ratios of groups exposed to norms against groups not exposed

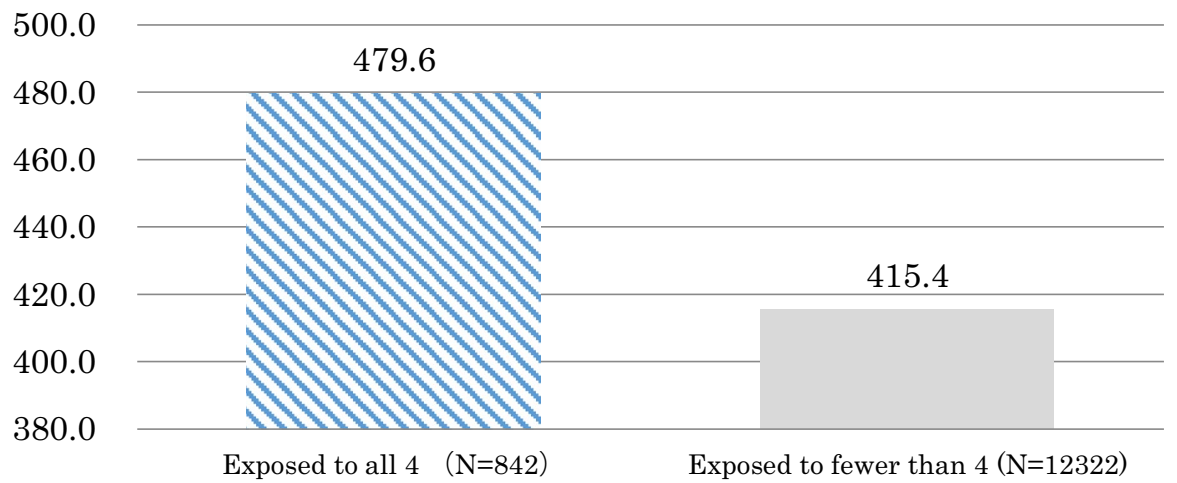

Fig. 2 Income comparison of the group exposed to the 4 norms and group exposed to fewer than the 4 norms

Factor 1 "Disinterest (Interest)", Factor 2 "Trust", Factor 3 "Norms", and Factor 4 "Independence". If an item had a negative coefficient for "Disinterest", it can be interpreted as showing "Interest" [16]. "Interest" is parental awareness and understanding of the circumstances of the child. "Trust" refers to parental confidence in the child and the presence of parental love. "Norms" reflects the extent to which parents clarified "things the child must not do". "Independence" indicates the degree to which children made decisions themselves.

The seven original items were listed in Table 3. 
Table 3 Questionnaire related with the relation with parents

\begin{tabular}{ll}
\hline & Questionnaire \\
\hline 1 & When I was a child, my parents or a close adult would read books to me \\
2 & When I was a child, my parents or a close adult would help me with my studies \\
3 & When I was a child, my whole family would go on outings together \\
4 & When I was a child, I (we) usually ate the evening meal without my (our) parents \\
5 & When I was a child, I was usually scolded/reproved by close adults other than my parents \\
6 & When I was a child, I was often/sometimes struck by my parents \\
7 & When I was a child, my parents often/sometimes scolded/reproved me \\
\hline
\end{tabular}

By applying factor analysis, we extracted the factor "Experience of Time Shared" from the first four questions and the factor "Exposure to Scolding/Reproval" from the last three questions.

Six factors thus extracted were used to determine parenting types, but the effect of individual factors on parent-child relations is not necessarily the most relevant point. For example, when a parent scolds a child, the manner in which the child received the scolding differs depending on the circumstances and how it is given. A scolding delivered with anger, irritation, or other similar emotion may lead the child to think he is not wanted. In contrast, when the child is admonished calmly for having done something inappropriate, he or she may be more likely to learn that the behavior was not appropriate rather than taking it personally. Assessing parenting requires an evaluation of a combination of multiple factors that express how the parents interact with a child and the characterization of parenting types.

For each respondent, the factor score was calculated for the six factors (interest, trust, norms, independence, time shared, scolding/reproval) characterizing parenting applied during childhood. For each factor, we calculated the interquartile ranges of factor scores and classified them in three stages: low exposure ( $<1$ st quartile), moderate exposure (between the 1st and 3rd), and high exposure ( $>3 \mathrm{rd}$ ). The degree of exposure to "Scolding/Reproval" was similarly considered in terms of severity and categorized as severe, somewhat severe, or not severe. Given these factors, we defined parenting types as follows: ${ }^{2}$

1. Supportive High or moderate independence, high trust, high interest, high time shared.

\footnotetext{
${ }^{2}$ Kim et al. [12] categorized parenting types as supportive, strict, easygoing, and harsh. Our categorization of parenting types adopted supportive, strict, and harsh from Kim et al. [12] but replaced easygoing with permissive and uninvolved. Kim et al. [12] used Latent Profile Analysis, a type of cluster analysis, to classify all respondents into one of the four parenting types. We used factor analysis to extract factors and then defined parenting types through a combination of factor score levels. Although some respondents do not fit into any of our five parenting types, we believe this method clearly shows differences in success levels in adulthood for respondents exposed to the various `parenting types.
} 
Table 4 Parenting type, and the degree of achievements

\begin{tabular}{|c|c|c|c|c|c|}
\hline & \multirow{2}{*}{$\begin{array}{l}\text { No. of } \\
\text { respondents } \\
\text { by type }\end{array}$} & \multirow{2}{*}{$\begin{array}{l}\text { Worker aver- } \\
\text { age income } \\
\text { (JPY } 10,000)\end{array}$} & \multirow{2}{*}{$\begin{array}{l}\text { High-education } \\
\text { ratio }\end{array}$} & \multicolumn{2}{|l|}{ Well-being } \\
\hline & & & & $\begin{array}{l}\text { Positive think- } \\
\text { ing }\end{array}$ & Sense of security \\
\hline Supportive & 363 & $404.82(17.21)$ & $0.60(0.026)$ & $0.69(0.05)$ & $0.39(0.04)$ \\
\hline Strict & 277 & 391.63 (21.99) & $0.44(0.03)$ & $0.07(0.06)$ & $0.05(0.05)$ \\
\hline Permissive & 1277 & $356.24(8.98)$ & $0.49(0.014)$ & $0.13(0.02)$ & $0.20(0.02)$ \\
\hline Uninvolved & 116 & $324.44(26.78)$ & $0.27(0.041)$ & $-0.51(0.11)$ & $-0.34(0.09)$ \\
\hline Harsh & 92 & $260.00(25.29)$ & $0.33(0.049)$ & $-0.62(0.11)$ & $-0.66(0.12)$ \\
\hline Sample totals & 2125 & $364.17(7.08)$ & $0.49(0.011)$ & $0.15(0.02)$ & $0.15(0.02)$ \\
\hline
\end{tabular}

Note: Figures in parentheses are standard errors

2. Strict (Tiger) Low independence, moderate or high trust, severe or somewhat severe, moderate or high interest, high norms.

3. Permissive High trust, moderate trust, not severe, high or moderate time shared.

4. Uninvolved Low interest, not severe, low time shared, low norms.

5. Harsh Low interest, low independence, low trust, severe.

We examined average income, educational attainment, and well-being of respondents in adulthood for each parenting type. Average income refers to the pretax average annual income earned by employed respondents. Educational attainment was defined as high if the respondent had at least an undergraduate college degree, and high-education ratios were compared for each parenting type. For well-being, we used the Oxford Happiness Questionnaire of Hills and Argyle [11] and applied the principle factor method to responses to extract "Positive Thinking" and "Sense of Insecurity" [16], and used the average values of the scores of these factors for each parenting type. Negative values assigned to "Sense of Insecurity" were considered to be "Sense of Security" and are discussed as such. Table 4 shows the average values for pre-tax income, positive thinking, and a sense of insecurity/security for each parenting type.

The average income was highest with exposure to the supportive type of parenting, followed by strict, permissive, uninvolved, and harsh. The difference between supportive and strict was small, but the income associated with the harsh type was considerably lower. The supportive type also had the highest high-education ratio, followed by high levels for permissive and strict, and substantially lower levels for harsh and uninvolved.

In terms of well-being, supportive, permissive and strict types had positive values for both positive thinking and sense of security. Uninvolved and harsh had negative values for each of these categories of well-being, with the harsh group having the lowest scores for both categories. Success levels relating to parenting types.

For ease of comparison, Fig. 3 shows a radar chart with the parenting types drawn as linear transformations aligned with each of the four categories (income, positive thinking, sense of security, and educational attainment). The scale is normalized so the values range from 0 to 10 for all categories. As the chart shows, the supportive 


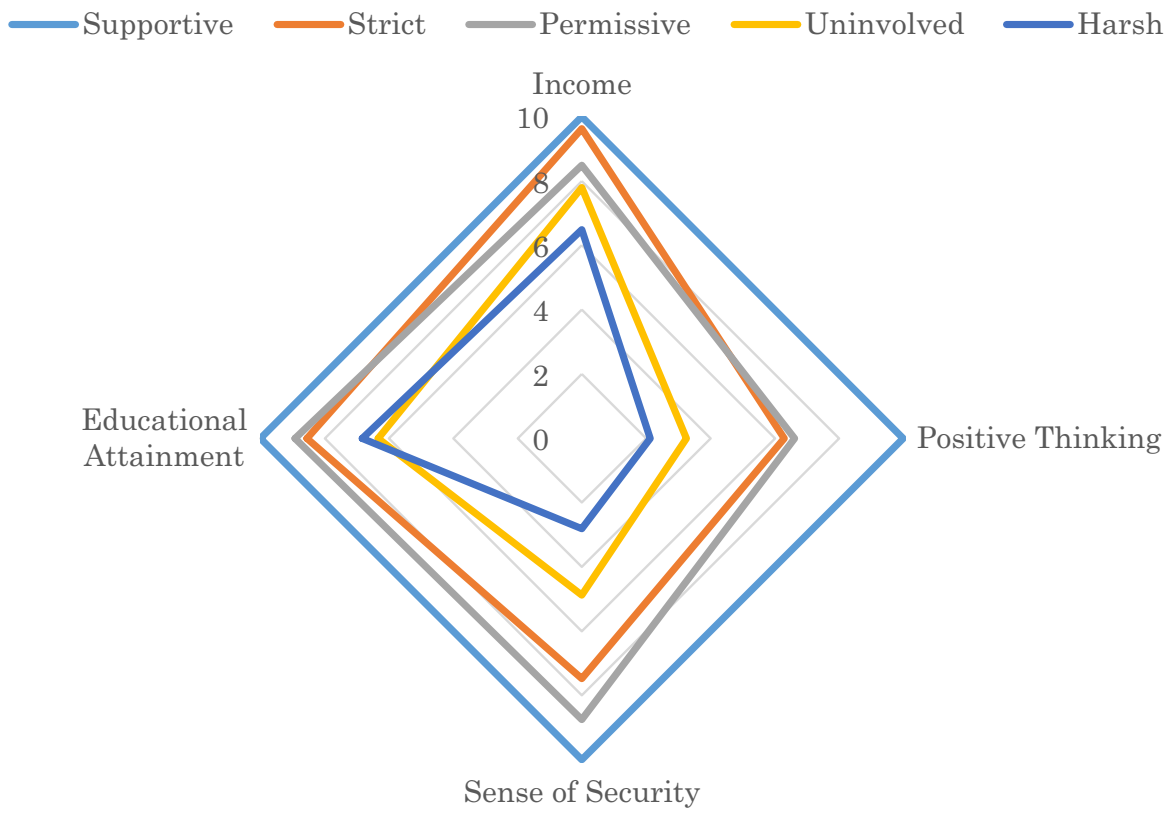

Fig. 3 Parenting methods and effects on adult success levels

parenting type has the highest levels in all categories, and it is substantially higher than the other parenting types in positive thinking. The strict and permissive types have similar shapes, although strict is higher in Income and but lower in a sense of security. Harsh shows the lowest success levels in all categories except educational attainment. Uninvolved and harsh are similar in shape.

\section{Manner of message delivery and formation of abilities}

In the previous section, the supportive group had the best performance in all categories, and the harsh group had the lowest. These differences may have resulted from differences in abilities formed through exposure to one or another parenting type during childhood. This section presents an analysis of adulthood capabilities evaluated by parenting type.

As part of the surveys undertaken for this study, respondents were asked questions relating to their abilities as members of society in terms of leadership and communication. A 5-point Likert scale ranging from 1 (none) to 5 (strong) was used in the answers. We applied the principal factor method to the survey results to the questionnaire in Table 5.

The first five questions in Table 5 were set as one factor, which is interpreted as leadership. And the last four questions were set as the other factor which is interpreted as communication ability. Table 6 summarizes these factors as they relate to the five parenting types. 
Table 5 Questionnaire related with the leadership and communication ability

\begin{tabular}{ll}
\hline & Questionnaire \\
\hline 1 & Ability to undertake and make progress with matters \\
3 & Ability to obtain the support of and involve others \\
4 & Ability to set goals and take firm action \\
5 & Ability to analyze present circumstances, resolve issues and reach targets \\
6 & Ability to clarify and prepare processes needed for resolution of problems \\
7 & Ability to relay my views comprehensibly \\
8 & Ability to listen carefully to the views of others \\
9 & Ability to acknowledge differences of opinion and different viewpoints \\
& Ability to recognize relationships between myself, and people and matters \\
\hline
\end{tabular}

Table 6 Parenting type, and ability as a member of society

\begin{tabular}{lrcc}
\hline & No. of people & $\begin{array}{l}\text { Average value expressing } \\
\text { ability }\end{array}$ & Standard error \\
\hline Leadership & & & \\
Supportive & 363.000 & 0.557 & 0.051 \\
Strict & 277.000 & 0.010 & 0.055 \\
Permissive & 1277.000 & 0.091 & 0.025 \\
Uninvolved & 116.000 & -0.414 & 0.099 \\
Harsh & 92.000 & -0.543 & 0.130 \\
Total & 2125.000 & 0.105 & 0.021 \\
Communication ability & & & 0.052 \\
Supportive & 363.000 & 0.500 & 0.057 \\
Strict & 277.000 & 0.094 & 0.025 \\
Permissive & 1277.000 & 0.092 & 0.101 \\
Uninvolved & 116.000 & -0.342 & 0.128 \\
Harsh & 92.000 & -0.580 & 0.021 \\
Total & 2125.000 & 0.109 & \\
\hline
\end{tabular}

Figure 4 shows a summary of the survey results, with Leadership on the horizontal axis and communication ability on the vertical axis. Of considerable interest is the fact that both factors are formed in parallel, with the coordinates of each parenting type basically located along a $45^{\circ}$ line, from harsh to uninvolved, strict, permissive, and then supportive.

There are many possible explanations for the results. Under the supportive parenting type, children may be responsible for proposing and taking action, whereas with the strict parenting type they may be more likely to take action under the direction of others. These tendencies could then emerge as differences in leadership ability in adulthood. Furthermore, with the supportive parenting type, children are encouraged to make their own decisions, whereas the tendency under the strict parenting 


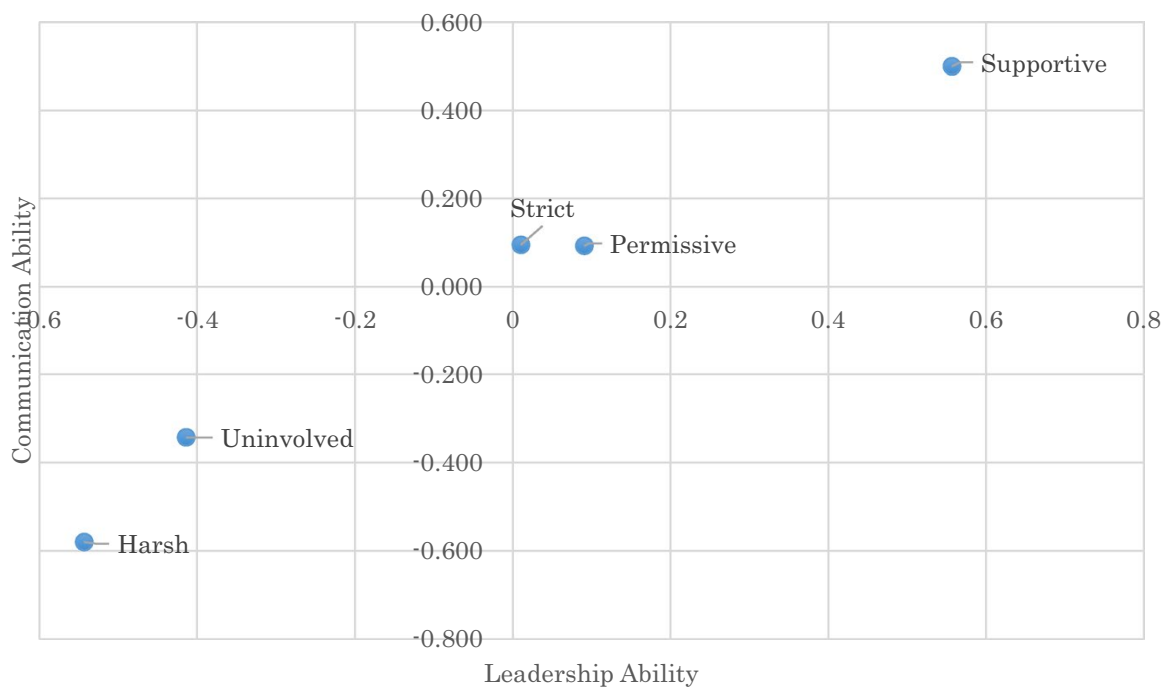

Fig. 4 Parenting type, and ability as a member of society

type is for children to make decisions within certain specified boundaries. Accordingly, exposure to the supportive parenting type may enable greater flexibility in understanding other people than exposure to the strict parenting type, and could thus be responsible for higher levels of communication ability. Under exposure to the Permissive type, children are not generally limited by parents, and both abilities are, therefore, positive.

\section{Characteristics of the strict parenting type}

The Strict parenting method drew a good deal of media attention after Chua [5] was published. However, as the analyses in Sects. 4 and 5 show, it had neither the best nor the worst performance of the five types. This raises the question of where the flaws and merits of the strict type of parenting can be found. In this section, we define characteristics of the strict parenting type through a comparison with the supportive type from the perspective of the degree to which each encourages a child's independence. We also compare the strict type with the harsh type in terms of the extent to which they try to control a child and the associated outcomes.

\section{Degree of independence}

Compared with the performance of adults exposed to the supportive parenting type, the performance of adults exposed to the strict parenting type in childhood is lower in all categories, particularly well-being. One difference in the factors determining whether a parenting type is supportive or strict is whether it encourages the child's independence. We divided the supportive-type respondents into two groups 
Table 7 Success levels according to degree of independence encouragement

\begin{tabular}{|c|c|c|c|c|c|}
\hline & \multirow[t]{2}{*}{ No. of people } & \multirow{2}{*}{$\begin{array}{l}\text { Worker aver- } \\
\text { age income } \\
(\mathrm{JPY} 10,000)\end{array}$} & \multirow{2}{*}{$\begin{array}{l}\text { High-education } \\
\text { ratio }\end{array}$} & \multicolumn{2}{|l|}{ Well-being } \\
\hline & & & & $\begin{array}{l}\text { Positive think- } \\
\text { ing }\end{array}$ & Sense of security \\
\hline $\begin{array}{l}\text { Supportive } \\
\quad \text { (strong } \\
\text { independence } \\
\text { encourage- } \\
\text { ment) }\end{array}$ & 86 & $435.06(33.367)$ & $0.733(0.048)$ & $0.820(0.109)$ & $0.204(0.094)$ \\
\hline $\begin{array}{l}\text { Supportive } \\
\text { (moderate } \\
\text { independence } \\
\text { encourage- } \\
\text { ment) }\end{array}$ & 277 & 394.87 (20.057) & $0.556(0.030)$ & $0.648(0.049)$ & $0.445(0.049)$ \\
\hline Strict & 277 & 391.63 (21.99) & $0.440(0.03)$ & $0.070(0.06)$ & $0.050(0.05)$ \\
\hline
\end{tabular}

Note: Figures in parentheses are standard errors

for comparison. One group was exposed to a high degree of encouragement toward independence; the other group was exposed to a moderate degree of encouragement. The group exposed to a high degree of independence encouragement featured higher scores in income, educational attainment, and positive thinking (Table 7). However, the high-encouragement group also had a higher sense of security. This finding suggests that, even within the supportive group, strong encouragement of independence may increase a sense of insecurity. Table 7 also shows the values for respondents exposed to the strict type of parenting, who receive little encouragement toward independence. This group scored the lowest values in terms of income, educational attainment, and positive thinking, and the lowest value for a sense of security. ${ }^{3}$ The presence or absence of encouragement toward independence is apparently an important factor influencing success levels in adulthood.

\section{Parental control attitudes}

Of the five parenting types, strict and harsh both take a stern approach toward children. However, in terms of both performance and well-being, the strict type leads to far more desirable results than the harsh type. The strict and harsh parenting types have high to moderate severity in common. We focused on the "controlling attitudes" parents take toward their children since that might have two types.

In our 2016 survey, we asked for responses to the following five questions related to parental control those are listed in Table 8.

Responses were given on a 5-point Likert scale: 1-never, 2-once or occasionally, 3-about half of the time, 4-frequently, and 5-always. The same exact

\footnotetext{
${ }^{3}$ Respondents exposed to the Harsh type received little encouragement toward independence and also scored low on all success levels.
} 
Table 8 Questionnaire related to the parental control

\begin{tabular}{ll}
\hline & Questionnaire \\
\hline 1 & Whenever I said something, my mother would change the way I said it \\
2 & My mother would put herself into any conversation and ignore what I was saying \\
3 & My mother would deny my opinion because it did not agree with opinion in her world \\
4 & If you love your mother, then do not do anything to cause her to worry \\
5 & My mother's attitude would change abruptly from kind to critical \\
\hline
\end{tabular}

Table 9 Success levels corresponding to paternal and maternal control levels (Total of male and female respondents)

\begin{tabular}{llcccc}
\hline & Control level & Strict (father) & Strict (mother) & Harsh (father) & Harsh (mother) \\
\hline Income (JPY10,000) & Low & 386.57 & 350.65 & 170.00 & 300.00 \\
& Medium & 387.62 & 334.04 & 257.89 & 150.00 \\
& High & 405.45 & 250.85 & 184.13 & 201.47 \\
Well-being & & & & \\
Positive thinking & Low & 0.25 & 0.08 & -0.75 & -0.04 \\
& Medium & 0.03 & 0.15 & -0.39 & -0.58 \\
& High & -0.06 & -0.12 & -0.67 & -0.68 \\
Sense of security & Low & 0.22 & 0.21 & -0.45 & -0.28 \\
& Medium & 0.03 & 0.08 & -0.78 & -0.84 \\
& High & -0.11 & -0.22 & -0.65 & -0.64 \\
High-education ratio & Low & 0.51 & 0.49 & 0.50 & 0.33 \\
& Medium & 0.38 & 0.43 & 0.26 & 0.28 \\
& High & 0.49 & 0.42 & 0.32 & 0.34 \\
\hline
\end{tabular}

questions were also asked substituting "father" for "mother". By applying the principal factor method, we extracted factors that can be interpreted as maternal/paternal "Control Level" We considered group below the 1st quartile as low, between the 1st and 3rd quartiles as a medium, and those above the 3rd quartile as high.

Table 9 shows the results corresponding to strict and harsh parenting for mothers and fathers separately. Under the strict type, income rose slightly as the father control level rose, but it declined as control increased for the mother. The same control level thus had different effects on levels of success, depending on whether it was applied by the father or the mother.

A low control level for the father in the strict parenting type had the highest value for positive thinking, but the value was low if either the mother or the father had high control level. Generally, respondents exposed to the harsh parenting type tended toward a low level of positive thinking. Furthermore, the degree of positive thinking decreased as the mother's control level rose.

Sense of security in the strict type was highest when either the mother or the father had low control levels, and sense of security in the harsh type was lower 


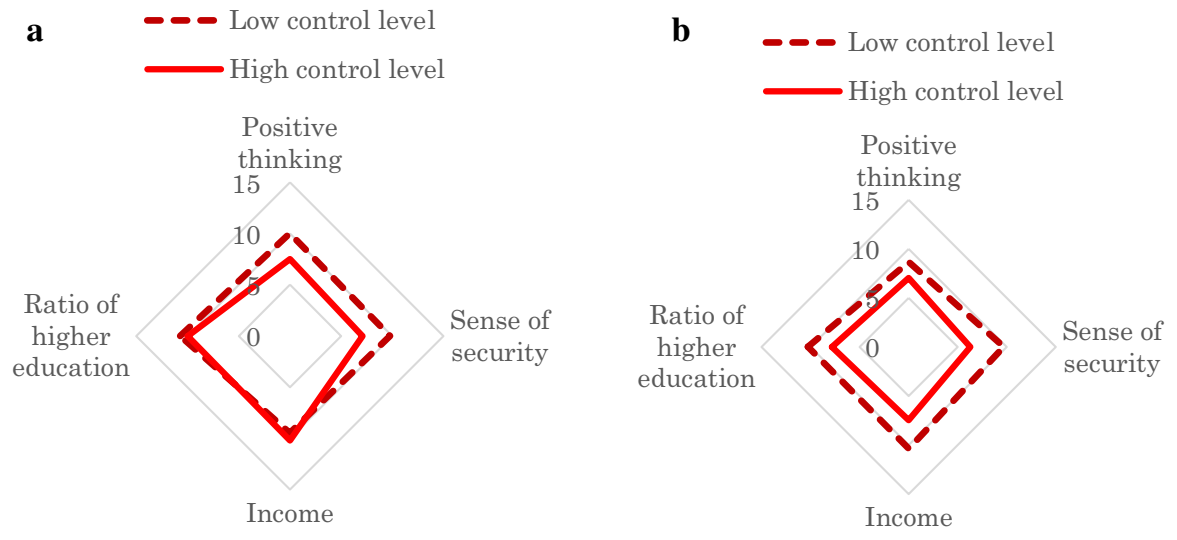

Fig. 5 a Strict father. Control level and success level. b Strict mother. Control level and success level

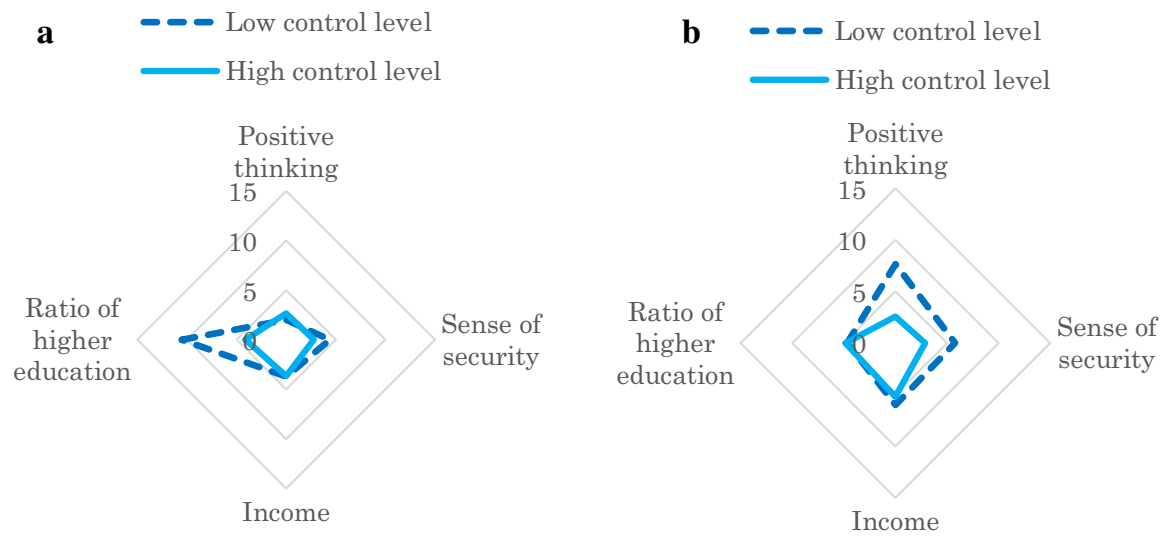

Fig. 6 a Harsh father. Control level and success level. b Harsh mother. Control level and success level

at every level as compared with the strict group. The high-education ratio (university graduate or higher) was highest when the control level of the strict-type mother or father was low.

Figures 5 and 6 are radar charts showing visual summaries of the results from the analysis of strict and harsh types. As shown in Fig. 5, with the strict type, a high control level by the father is associated with lower values in positive thinking and sense of security, whereas a high control level by the mother has lower levels of success in all categories. For the harsh type (Fig. 6), a high control level has a lower success level in all categories for both parents. When the father has a low control level, educational attainment is higher. When the mother has a low 


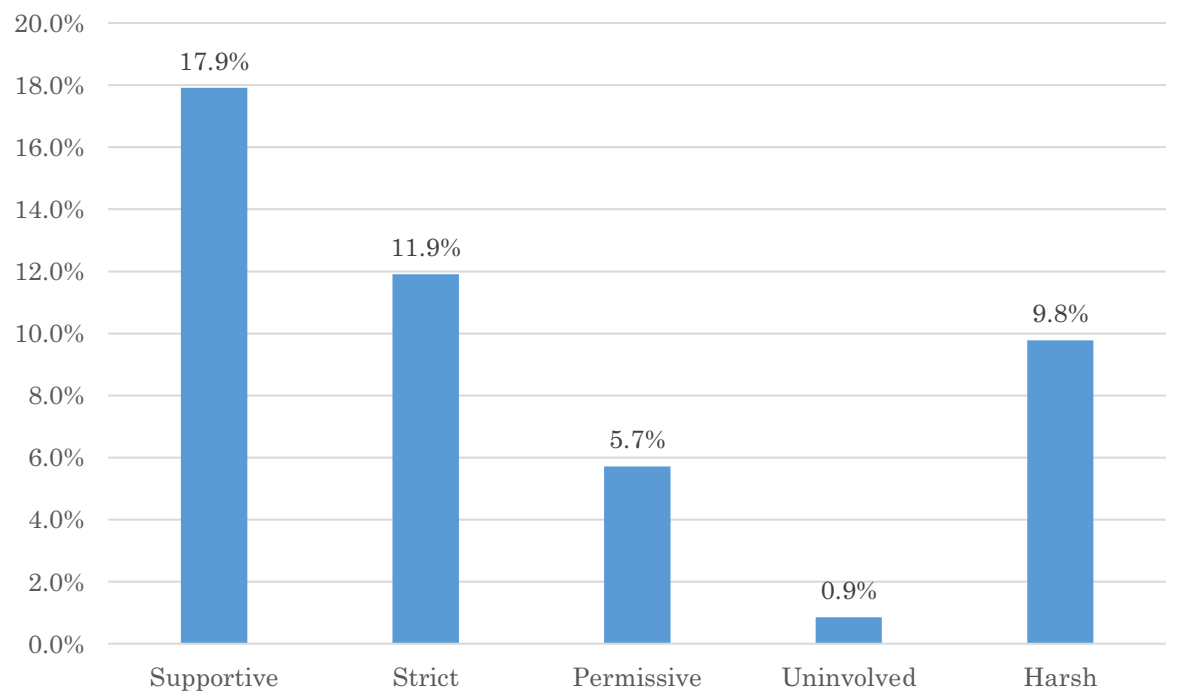

Fig. 7 Proportion of people exposed to all four norms

control level, positive thinking and sense of security are higher, as compared with the high control level. ${ }^{4}$

\section{Parenting type and effective norm messages}

In which parenting type are parents most likely to teach their children the four basic norms discussed in Sect. 3 ("Do not lie", "Be kind to others", "Follow the rules", and "Study")? Fig. 7 shows the ratios of respondents who were exposed to all four norms in each parenting type. The ratios of respondents exposed to all four norms were low in permissive and uninvolved and increased (in order) from harsh to strict to supportive.

\section{Manner of message delivery and family perspective in adulthood}

How children receive parental messages may affect performance in adulthood. There is a risk that responses to direct survey questions on how parental messages were received may carry strong biases, depending on the respondent's assessment of the messages. We, therefore, used an indirect approach to assess this question. Specifically, we posed the statement "My father (mother) is the ideal man (woman),"

\footnotetext{
${ }^{4}$ We also examined control levels for fathers and mothers who applied the Supportive type of parenting. Levels of success were highest in all categories, and the trends were roughly similar to those of the Strict type. 
Table 10 Cross table showing views of father as ideal man, according to parenting type and respondent gender

\begin{tabular}{|c|c|c|c|c|c|}
\hline & Supportive & Strict & Permissive & Uninvolved & Harsh \\
\hline \multicolumn{6}{|l|}{ Male } \\
\hline \multicolumn{6}{|l|}{ Agree } \\
\hline No. of people & 63 & 19 & 138 & 3 & 2 \\
\hline Ratio (\%) & 44.10 & 16.70 & 23.90 & 4.40 & 5.60 \\
\hline \multicolumn{6}{|l|}{ Yes and no } \\
\hline No. of people & 47 & 39 & 249 & 20 & 1 \\
\hline Ratio (\%) & 32.90 & 34.20 & 43.10 & 29.40 & 2.80 \\
\hline \multicolumn{6}{|l|}{ Disagree } \\
\hline No. of people & 33 & 56 & 191 & 45 & 33 \\
\hline Ratio (\%) & 23.10 & 49.10 & 33.00 & 66.20 & 91.70 \\
\hline \multicolumn{6}{|l|}{ Female } \\
\hline \multicolumn{6}{|l|}{ Agree } \\
\hline No. of people & 128 & 44 & 225 & 8 & 4 \\
\hline Ratio (\%) & 58.20 & 27.00 & 32.20 & 16.70 & 7.10 \\
\hline \multicolumn{6}{|l|}{ Yes and no } \\
\hline No. of people & 44 & 45 & 250 & 10 & 3 \\
\hline Ratio (\%) & 20.00 & 27.60 & 35.80 & 20.80 & 5.40 \\
\hline \multicolumn{6}{|l|}{ Disagree } \\
\hline No. of people & 48 & 74 & 224 & 30 & 49 \\
\hline Ratio (\%) & 21.80 & 45.40 & 32.00 & 62.50 & 87.50 \\
\hline
\end{tabular}

and calculated the ratios of respondents who indicated "I tend to think so" and "I strongly think so" for each parenting type.

Table 10 shows the results for fathers. As compared with the strict type, a higher proportion of respondents exposed to supportive type parenting considered their fathers to be the ideal man. Almost no respondents regarded their fathers as the ideal man in the harsh group. Table 11 shows the results for mothers. As compared with the strict type, a higher proportion of respondents exposed to supportive type parenting thought of their mothers as the ideal woman, particularly among females. As was the case for fathers, the mother was almost never regarded as the ideal woman in the harsh group.

From this perspective, the most favorable parent-child relationships appear to be built in the supportive type group with both fathers and mothers, irrespective of the gender of the child.

Next, we examined how "seeing parents in a positive light" affected inclination toward having a family and children. Figures 8 and 9 categorize respondents who indicated the father (mother) was the ideal man (woman), according to age group and ratio of marital status. The rate of marriage was highest in all age groups of respondents who considered their fathers (mothers) to be the ideal man (woman).

Tables 12 and 13 show the number of children desired by the respondents, categorized according to the extent to which the father (mother) is seen as the ideal 
Table 11 Cross table showing views of mother as ideal woman, according to parenting type and respondent gender

\begin{tabular}{|c|c|c|c|c|c|}
\hline & Supportive & Strict & Permissive & Uninvolved & Harsh \\
\hline \multicolumn{6}{|l|}{ Male } \\
\hline \multicolumn{6}{|l|}{ Agree } \\
\hline No. of people & 59 & 28 & 150 & 6 & 0 \\
\hline Ratio (\%) & 41.30 & 24.60 & 26.00 & 8.80 & 0.00 \\
\hline \multicolumn{6}{|l|}{ Yes and no } \\
\hline No. of people & 50 & 37 & 255 & 19 & 1 \\
\hline Ratio (\%) & 35.00 & 32.50 & 44.10 & 27.90 & 2.80 \\
\hline \multicolumn{6}{|l|}{ Disagree } \\
\hline No. of people & 34 & 49 & 173 & 43 & 35 \\
\hline Ratio (\%) & 23.80 & 43.00 & 29.90 & 63.20 & 97.20 \\
\hline \multicolumn{6}{|l|}{ Female } \\
\hline \multicolumn{6}{|l|}{ Agree } \\
\hline No. of people & 158 & 59 & 282 & 4 & 1 \\
\hline Ratio (\%) & 71.80 & 36.20 & 40.30 & 8.30 & 1.80 \\
\hline \multicolumn{6}{|l|}{ Yes and no } \\
\hline No. of people & 41 & 49 & 246 & 12 & 6 \\
\hline Ratio (\%) & 18.60 & 30.10 & 35.20 & 25.00 & 10.70 \\
\hline \multicolumn{6}{|l|}{ Disagree } \\
\hline No. of people & 21 & 55 & 171 & 32 & 49 \\
\hline Ratio (\%) & 9.50 & 33.70 & 24.50 & 66.70 & 87.50 \\
\hline
\end{tabular}

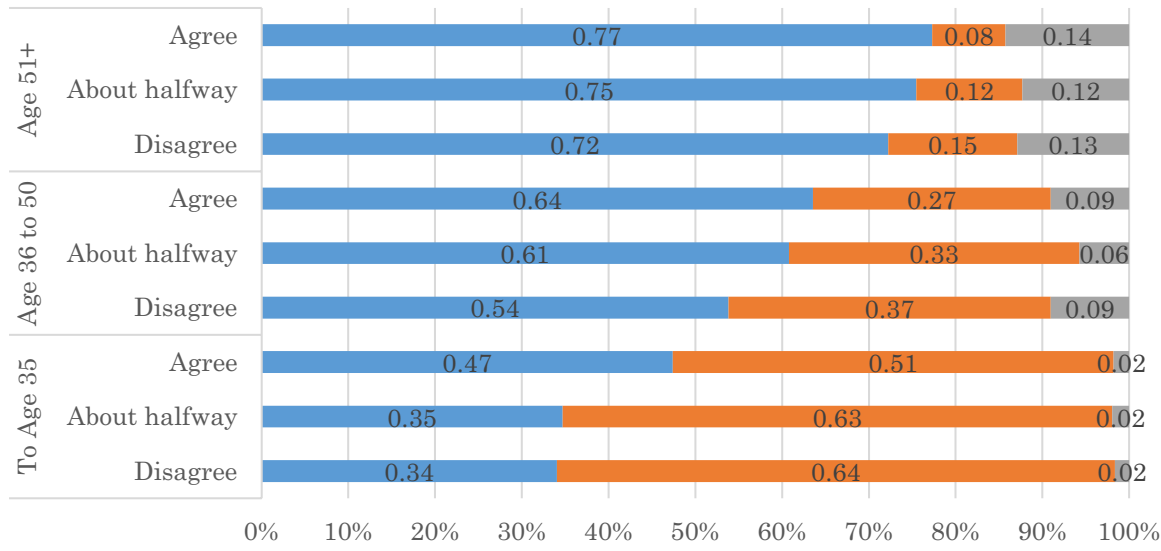

\section{- Married Unmarried Devorce/bereavement}

Fig. 8 Regard father as the ideal man, and marital status

man (woman). The respondents in the groups who view their father (mother) as the ideal man (woman) desired a greater number of children as compared with both of the other groups. 


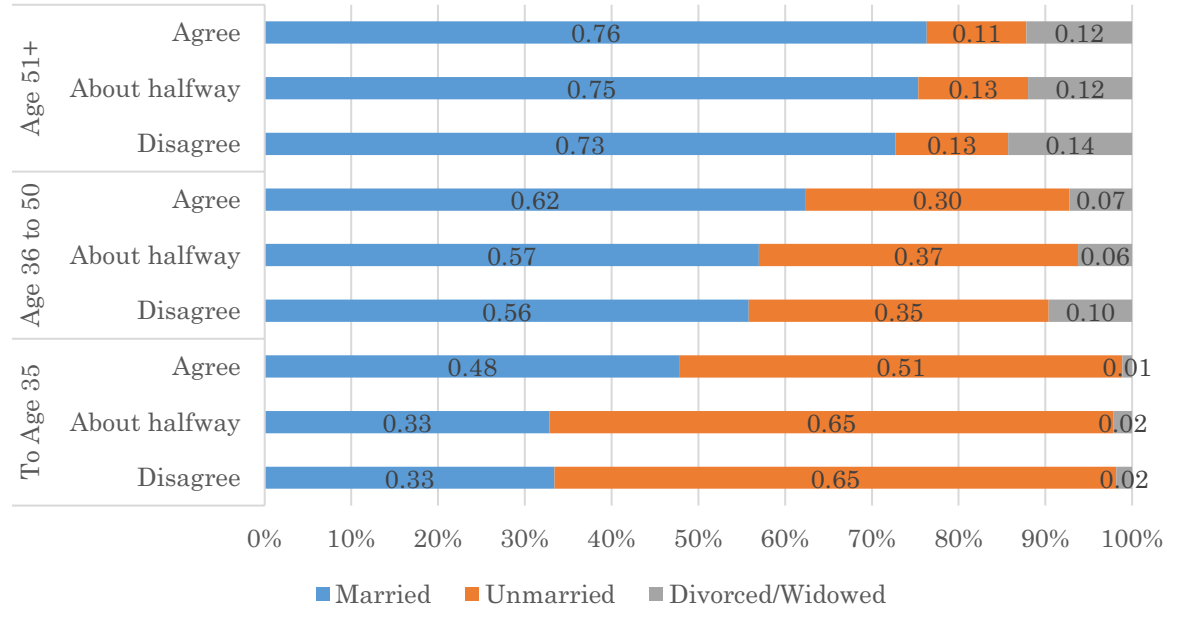

Fig. 9 Regard mother as the ideal woman, and marital status

Table 12 View father as the ideal man, and number of children desired

Table 13 View mother as the ideal woman, and number of children desired

\begin{tabular}{lcll}
\hline & No. of people & $\begin{array}{l}\text { Average number } \\
\text { of children } \\
\text { desired }\end{array}$ & Standard error \\
\hline Agree & 1963 & 2.93 & 0.027 \\
About halfway & 3318 & 2.79 & 0.023 \\
Disagree & 4719 & 2.68 & 0.020 \\
Total & 10,000 & 2.77 & 0.013 \\
\hline
\end{tabular}

Note: All differences are statistically significant at the $1 \%$ significance level

\begin{tabular}{lcll}
\hline & No. of people & $\begin{array}{l}\text { Average number } \\
\text { of children } \\
\text { desired }\end{array}$ & Standard error \\
\hline Agree & 2341 & 2.87 & 0.024 \\
About halfway & 3425 & 2.74 & 0.023 \\
Disagree & 4234 & 2.73 & 0.021 \\
Total & 10,000 & 2.77 & 0.013 \\
\hline
\end{tabular}

Note: The difference between "About Halfway" and "Disagree" alone is insignificant; the differences between "Agree", "About Halfway" and "Disagree" are significant at the $1 \%$ significance level

Finally, we undertook an overall analysis of differences in parenting type and perspectives of family. In addition to the ideal parent, marriage ratio, and number of desired children, Fig. 10 illustrates the level of inclination toward taking care of parents in their later years by parenting type. 

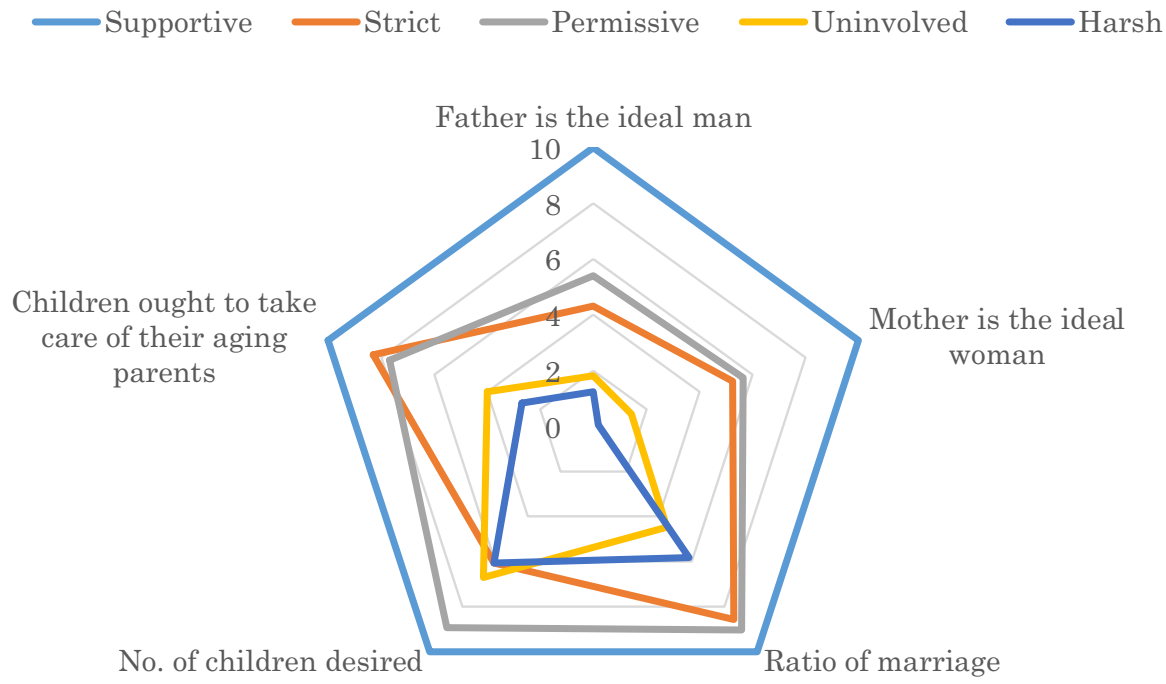

Fig. 10 Parenting type and family perspective

As this figure shows, the supportive type has the highest values in all categories, indicating the most positive family perspective. The comparison of the strict and permissive types in Fig. 3 showed a higher level of income for the strict type, but almost no difference between the two in educational attainment and positive thinking. However, strict exceeds permissive only in "Children ought to take care of their aging parents" and is substantially lower in "Number of children desired" (Fig. 10). Similar to their relative positioning in Fig. 3, Uninvolved and harsh show the most negative family perspectives on these criteria.

\section{Conclusion}

In this paper, we demonstrated the effectiveness of a new method of analysis of how parenting methods later relate to personality formation and social success in adulthood. That is, Using questionnaire surveys targeting Japanese adults, we elicited their recollections of childhood and analyzed the relationships the respondents had with their parents during childhood. For this purpose, we examined the effects of the type of parenting applied to children on their adult performance according to three categories of characteristics: (1) the norm messages given to the child, (2) how the messages were delivered to the child, and (3) how the child received the messages.

We found that the following four norm messages were associated with a child's successful performance in the labor market as an adult: "Be kind to others", "Do not tell lies", "Follow the rules", and "Study". A possible explanation is that these norm messages cultivate altruistic thinking, nurture trust, and heighten sociability.

In analyzing the effects of the ways in which parents' values and behavior patterns are transmitted to children, we classified parenting methods into five types: 
supportive, strict, permissive, uninvolved, and harsh. We then compared average income, well-being (positive thinking, sense of security), and educational attainment among the groups of respondents exposed to one or another of the parenting types. Of the five parenting types, the supportive type showed the highest levels of success in all categories, and the harsh type showed the lowest. Additionally, we examined leadership and communication ability as measures of abilities possessed by individuals in adulthood. The outcomes were highest in the Supportive group, as expected, and declined in order of parenting type from permissive to strict to uninvolved to harsh.

Recently, the strict type of parenting has drawn increasing attention through discussions of the "Tiger Mother" concept posed by Chua [5]. The results showed that the performance of the strict group was neither the lowest nor the highest across all categories. We examined features of the strict type and compared them with the supportive type and the harsh type. Specifically, we compared supportive and strict on the extent to which each encourages independence of the child to see how it affected outcomes in adulthood, and harsh and Strict for the outcome of the intensity level of controlling attitudes of parents toward children. The results showed the importance of building parent-child trust and encouraging independence while sharing time with children.

Characteristics of the ways in which a child receives messages from parents were defined by questioning respondents on the extent to which they see their fathers (mothers) as the ideal man (woman). The group exposed to the supportive type of parenting had the highest ratio of respondents who identified their fathers (mothers) as the ideal man (woman). In contrast, the lowest ratio was observed in the harsh group. Respondents who considered their fathers (mothers) to be the ideal man (woman) and were exposed to supportive parenting had the highest rate of marriage and the highest number of desired children. Additionally, respondents in the supportive group had the greatest inclination toward taking care of aging parents, and those in the harsh group had the lowest.

These empirical results showed that the ways in which messages are passed from parents to children can have material and long-term effects upon the children later in their lives. This conclusion is valid also for messages themselves, for the patterns of message delivery, and for how the messages are received. The results show the method of empirical analysis introduced in this paper can be effective in evaluating the role of education in the home in future studies.

Funding This paper is an outcome of one facet of the project "Fundamental Research for Economic Growth and Productivity Improvement in Japan," sponsored by the Research Institute of Economy, Trade and Industry. Additionally, this work was supported by the Japan Society for the Promotion of Science, Grant-in-Aid for Specially Promoted Research \#23000001, Grants-in-Aid for Research \#15H05729 and $\# 16 \mathrm{H} 03598$. We thank an anonymous referee for comments on the earlier version of the paper.

\section{Compliance with ethical standards}

Conflict of interest On behalf of all authors, the corresponding author states that there is no conflict of interest. 
Open Access This article is licensed under a Creative Commons Attribution 4.0 International License, which permits use, sharing, adaptation, distribution and reproduction in any medium or format, as long as you give appropriate credit to the original author(s) and the source, provide a link to the Creative Commons licence, and indicate if changes were made. The images or other third party material in this article are included in the article's Creative Commons licence, unless indicated otherwise in a credit line to the material. If material is not included in the article's Creative Commons licence and your intended use is not permitted by statutory regulation or exceeds the permitted use, you will need to obtain permission directly from the copyright holder. To view a copy of this licence, visit http://creativecommons.org/licen ses/by/4.0/.

\section{References}

1. Armsden, G.C., \& Greenberg, M.T. (1987). The inventory of parent and peer attachment: individual differences and their relationship to psychological well-being in adolescence. Journal of Youth and Adolescence, 16(5), 427-454.

2. Barber, B.K. (1996). Parental psychological control: revisiting a neglected construct. Child Development, 67(6), 3296-3319.

3. Baumrind, D. (1967). Child care practices anteceding three patterns of preschool behavior. Genetic Psychology Monographs, 75(1), 43-88.

4. Baumrind, D. (1968). Authoritarian vs. authoritative parental control. Adolescence, 3, $255-272$.

5. Chua, A. (2011). Battle hymn of the tiger mother. New York: Penguin Press.

6. Fuligni, J. A., Tseng, V., \& Lam, M. (1999). Attitudes toward family obligations among American Adolescents with Asian, Latin American, and European Backgrounds. Child Development, 70(4), 1030-1044. (Jul.-Aug. 1999).

7. Ge, X., Best, K. M., Conger, R. D., \& Simons, R. L. (1996). Parenting behaviors and the occurrence and co-occurrence of adolescent depressive symptoms and conduct problems. Developmental Psychology, 32(4), 717-731.

8. Heckman, J. J. (2006). Skill formation and the economics of investing in disadvantaged children. Science, 312(5782), 1900-1902.

9. Heckman, J. J., \& Rubinstein, Y. (2001). The importance of noncognitive skills: lessons from the GED testing program. American Economic Review, 91(2), 145-149.

10. Heckman, J. J., Stixrud, J., \& Urzua, S. (2006). The effects of cognitive and noncognitive abilities on labor market outcomes and social behavior. Journal of Labor Economics, 24(3), 411-482.

11. Hills, P., \& Argyle, M. (2002). The Oxford Happiness Questionnaire: a compact scale for the measurement of psychological well-being. Personality and Individual Differences, 33, 1073-1082.

12. Kim, S. Y., Wang, Y., Orozco-Lapray, D., Shen, Y., \& Murtuza, M. (2013). Does 'Tiger Parenting' Exist? Parenting profiles of Chinese Americans and Adolescent Developmental Outcomes. Asian American Journal of Psychology, 4(1), 7-18.

13. Maccoby, E. E., \& Martin, J. A. (1983). Socialization in the context of the family: parent-child interaction. In P. Mussen (Ed.), Handbook of child psychology (4th ed.). New York: Wiley.

14. Meares, P. A., Blazevski, J., Bybee, D., \& Oyserman, D. (2010). Independent effects of paternal involvement and maternal mental illness on child outcomes. Social Service Review, 84(1), 103-127.

15. Nishimura, K., Hirata, J., Yagi, T., Urasaka, J. (2016). Basic morality and social success in Japan. Journal of Informatics and Data Mining, 1(1). https://datamining.imedpub.com/basic-morality-andsocial-success-in-japan.pdf (Insight Medical Publishing, Delaware, USA).

16. Nishimura, K., \& Yagi, T. (2017). How parenting affects children's futures: empirical study in Japan. Journalism and Mass Communication, 7(1), 35-45.

17. Sriram, R., \& Navalkar, P. G. (2012). Who is an 'Ideal' Father? Father, mother and children's views. Psychology and Developing Societies, 24(2), 205-237.

Publisher's Note Springer Nature remains neutral with regard to jurisdictional claims in published maps and institutional affiliations. 